\title{
ANÁLISE DAS INICIATIVAS DE PRODUÇÃO MAIS LIMPA PROMOVIDAS LABORATÓRIO DE CAMARÕES MARINHOS DA UNIVERSIDADE FEDERAL DE SANTA CATARINA
}

\section{ANALISYS ON THE CLEANER PRODUCTION INITIATIVES PROMOTED BY THE MARINE SHRIMP LABORATORY OF THE UNIVERSIDADE FEDERAL DE SANTA CATARINA}

\author{
Luciane Finger $^{1}$; Luis Moretto Neto ${ }^{2}$ \\ ${ }^{1}$ Sistema Federação das Indústrias do Estado do Paraná - FIEP- Curitiba - Brasil \\ luciane finger@yahoo.com.br \\ ${ }^{2}$ Universidade Federal de Santa Catarina - Florianópolis - Brasil \\ moretto@cse.ufsc.br
}

\begin{abstract}
Resumo
Com o advento da Revolução Industrial houve um aumento da oferta de produtos e do consumo de recursos naturais, gerando impactos ambientais que, após as décadas de 60 e 70, deram início a uma crescente preocupação ambiental. Empresas, governos e organizações não governamentais intensificaram suas atividades ambientais a partir da década de 90, elevando a importância dos conceitos de Gestão Ambiental e Produção mais Limpa. A fim de esclarecer a forma como esses processos ocorrem nas organizações pesquisou-se, neste trabalho, a aplicação das técnicas de produção mais limpa no Laboratório de Camarões Marinhos da Universidade Federal de Santa Catarina. Este se caracteriza como um estudo descritivo, bibliográfico, documental e estudo de caso, com caráter qualitativo. Analisou-se as atividades ambientais do laboratório, possibilitando a constatação de que suas iniciativas não tiveram como foco apenas o controle da poluição, estando de acordo com a proposta do conceito de produção mais limpa. Verificou-se, porém, a influência determinante de fatores externos sobre o seu Sistema de Gestão Ambiental, que o prejudicaram decisivamente, inclusive com a perda da certificação pela ISO14000.
\end{abstract}

Palavras-chave: produção mais limpa; sistema de gestão ambiental; controle da poluição.

\section{Introdução}

O surgimento da Revolução Industrial, em meados do século XVIII, implicou na substituição do consumo doméstico - focado na utilização do que se plantava e elaborava pelas próprias famílias, ou na troca com pequenos comércios - pela economia do consumo em massa, a qual prevalece até a atualidade, em função da grande oferta de produtos gerada pela produção em escala.

A elevação da oferta de produtos e serviços exige das indústrias, consequentemente, o aumento do consumo de recursos naturais para a sua utilização na produção. Além disso, não era 
apenas o consumo exacerbado de recursos naturais que estava - e ainda está - afetando o meio ambiente, mas também a geração de resíduos em grande escala e a sua disposição inadequada, feita de maneira totalmente irresponsável.

A partir das décadas de 60 e 70, em decorrência disso, deu-se início a diversas campanhas de conscientização ambiental, tendo sido publicados livros, relatórios, e realizadas conferências de nível mundial sobre o meio ambiente. Gradativamente, as Nações, e também as empresas, passaram a demonstrar maior preocupação com o impacto que causam sobre o meio ambiente, e a realizar ações que fossem condizentes com a meta de desenvolvimento sustentável, surgindo assim a gestão ambiental. A partir da década de 1990, em consequência, foram diversas as iniciativas empresariais, governamentais e não governamentais, visando à disseminação das políticas ecologicamente corretas.

Objetivando se tornar uma empresa ambientalmente responsável, é importante a adoção de um Sistema de Gestão Ambiental (SGA), que consiste em um processo voltado a resolver, reduzir e/ou prevenir esses problemas de caráter ambiental, com o objetivo de alcançar um desenvolvimento sustentável (CALLENBACH et al., 1993). O sistema mais conhecido é o baseado nas normas da série ISO 14001, que possibilita a alocação de recursos, definição de responsabilidades e avaliação contínua de práticas, procedimentos e processos, em busca da melhoria contínua do desempenho ambiental da empresa (RENSI, 2006).

Dentre os meios utilizados para o alcance dos objetivos do SGA menciona-se o uso de tecnologias limpas e a preocupação com o impacto ambiental da organização durante toda a vida útil de seus produtos ou serviços, bem como de seus processos produtivos. Adota-se, assim, uma política preventiva, denominada Produção mais Limpa.

Um exemplo de organização que considerou o seu impacto sobre o meio ambiente é o do Laboratório de Camarões Marinhos da Universidade Federal de Santa Catarina, localizado em Florianópolis - SC. O LCM adquiriu em 2003 o certificado de adequação às normas ISO 14001, o qual foi mantido até o ano de 2006, quando o surgimento da chamada "Síndrome da Mancha Branca" fez com que fosse paralisada a produção de camarões no período de 2005 a 2008. O nível de produção atual não foi normalizado, porém algumas das iniciativas de Produção mais Limpa implementadas durante o período de certificação foram mantidas.

A partir da verificação da crescente preocupação mundial com as questões ambientais, e das iniciativas de adequação do Laboratório de Camarões Marinhos a essas exigências durante seu período de certificação ambiental, acredita-se ser pertinente a análise das ações dessa natureza na organização supracitada. Com isso, busca-se, nesse artigo, analisar os processos de produção mais limpa do Laboratório de Camarões Marinhos da Universidade Federal de Santa Catarina. 


\section{Gestão Ambiental}

Apesar da produção em escala e do aumento do consumo de recursos naturais surgido a partir da Revolução Industrial, as empresas continuaram demonstrando reatividade em relação às questões ambientais, agindo em sua maioria forçadas pela legislação (LUSTOSA, 2003). A responsabilidade ambiental era considerada apenas uma função para evitar acidentes locais, controlar a poluição e colaborar na prevenção, sendo uma resposta a multas e sanções (MAIMON, 1996).

As alterações ocorridas no mercado internacional em função das grandes conferências mundiais sobre o meio ambiente fizeram com que algumas empresas empregassem atitudes proativas, utilizando técnicas menos agressivas, antecipando-se às regulamentações ambientais ou implantando sistemas de gerenciamento ambiental. Elas passaram a compreender que suas ações não poderiam se limitar ao consumo desenfreado dos recursos naturais, o que levou ao aprimoramento das relações com a comunidade, com a opinião pública e com o movimento ambientalista (LUSTOSA, 2003).

Com essa mudança de pensamento percebe-se que, a partir dos anos 90, caracterizou-se uma nova fase de integração da gestão ambiental em organizações industriais, cujas características compreendem a introdução progressiva de uma perspectiva de sustentabilidade; a proliferação dos engajamentos coletivos; a maior interação entre as esferas pública e privada; e o maior envolvimento da sociedade civil organizada (CORAZZA, 2003). A responsabilidade ambiental passou, então, a ser parte da gestão administrativa de algumas empresas, atingindo as mais altas esferas de decisão, e deixando de ser uma função exclusiva da produção para tornar-se uma função da administração (MAIMON, 1996).

Existem diversas propostas de normas de gestão ambiental que padronizam as políticas de responsabilidade ambiental das empresas, sendo algumas homologadas pelos órgãos normativos de determinados países (MAIMON, 1999). O mais conhecido e utilizado no Brasil é o Sistema de Gestão Ambiental com base na série ISO 14001.

O Sistema de Gestão Ambiental é um instrumento que possibilita às organizações a alocação de recursos, a definição de responsabilidades, bem como a avaliação contínua de práticas, procedimentos e processos, buscando a melhoria contínua do seu desempenho ambiental (RENSI, 2006). O Instituto Brasileiro de Produção Sustentável e Direito Ambiental (IBPS) acrescenta que o Sistema de Gestão Ambiental "integra o sistema de gestão global de uma organização, que inclui, entre outros, estrutura organizacional, atividades de planejamento, responsabilidades, práticas, procedimentos, processos e recursos para implementar e manter uma política ambiental” (IBPS, $2008, \mathrm{~s} / \mathrm{p})$. 
A preocupação com a gestão ambiental da empresa deve englobar a análise de todo o ciclo de vida de seus produtos, bem como dos processos produtivos que realiza, em busca da prevenção de geração de resíduos e de emissão de poluentes. A essa gestão ecológica preventiva denomina-se Produção mais Limpa.

\section{Produção mais Limpa}

De acordo com o Guia da Produção mais Limpa (2009), esse termo consiste na aplicação contínua de uma estratégia ambiental de prevenção da poluição na empresa, focando produtos e processos, a fim de otimizar o emprego de matérias-primas de modo a não gerar ou a minimizar a geração de resíduos, reduzindo os riscos ambientais e gerando benefícios econômicos para a empresa.

Essa definição é complementada por PNUMA (1993, apud BARBIERI, 2008), que indica que a expressão Produção mais Limpa consiste em uma abordagem de produção mais ampla, pois considera todas as fases do processo de manufatura e o ciclo de vida do produto, incluindo seu consumo. O ciclo de vida engloba a etapa do fornecimento, a fabricação, a distribuição, o consumo e a destinação final. A análise do ciclo de vida dos produtos, portanto, considera que todo o uso de recursos é uma entrada, e subdivide as saídas entre os produtos fabricados e as emissões feitas para o ar, terra e água durante o ciclo de vida completo do produto.

Dentre as ações empresariais compatíveis com a produção mais limpa estão aquelas voltadas à economia de energia e matérias-primas, à substituição de recursos não renováveis por renováveis, à eliminação do uso de substâncias tóxicas, à redução de desperdícios e da poluição resultante tanto do processo produtivo como da utilização dos produtos, por parte do consumidor. Ou seja, a produção mais limpa engloba mudanças nos produtos e nos seus processos de produção a fim de reduzir ou eliminar os rejeitos deles criados.

Figueiredo (2004) destaca que as tecnologias ambientais convencionais trabalham principalmente no tratamento de resíduos e emissões existentes, atuando no final do processo de produção, através das técnicas denominadas "fim-de-tubo", consideradas ações corretivas. Cardoso (2004, apud RENSI, 2006, p. 86) acrescenta que se entende por fim de tubo "as tecnologias de controle da poluição (tratamento de resíduos sólidos, efluentes líquidos e emissões atmosféricas) utilizadas ao final dos processos produtivos para atender exigências legais”. Estas tecnologias, portanto, geram despesas adicionais para a empresa, como, por exemplo, com a instalação de filtros ou estações de tratamento. Já no caso da Produção mais Limpa, o processo é diferenciado, pois ela integra os objetivos ambientais ao processo; reduz a geração de resíduos durante todo o processo produtivo, minimizando os custos com tratamentos de poluentes e as emissões ao meio ambiente. 
Percebe-se, então, que a palavra-chave da produção mais limpa, e o que a diferencia do controle de poluição tradicional é justamente o enfoque na prevenção.

A estratégia de Produção mais Limpa pode ser visualizada através do fluxograma a seguir.

Figura 1- Fluxograma da estratégia de Produção mais Limpa

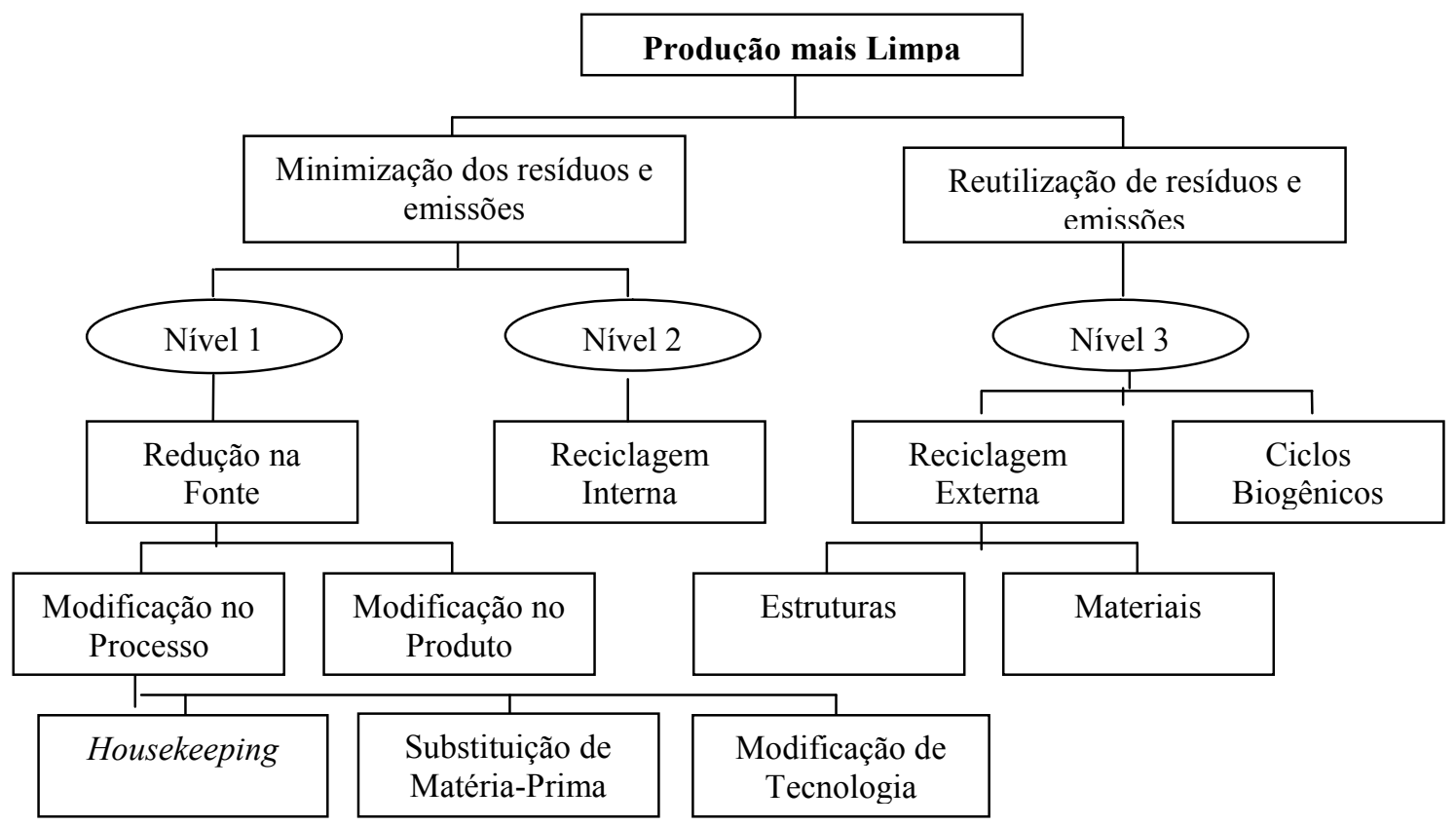

Fonte: CNTL - Centro Nacional de Tecnologias Limpas (2009)

A prioridade da Produção mais Limpa corresponde à minimização dos resíduos e emissões, no nível 1 do fluxograma. A figura demonstra que, no nível 1 , o qual indica a necessidade de redução de geração de resíduos e emissões na fonte, três aspectos devem ser considerados: Housekeeping, substituição de matéria-prima e modificação de tecnologia. Silva (2004) explica o significado destes termos:

- Housekeeping: realização de limpezas periódicas, uso cuidadoso de matérias-primas e com o processo, alterações no arranjo físico - disposição mais adequada de máquinas e equipamentos visando a redução de desperdícios -, elaboração de manuseio de materiais e recipientes, dentre outras técnicas que permitam mudanças nas condições operacionais;

- Substituição de matérias-primas e de processos: identificação de materiais mais resistentes que possam vir a reduzir perdas por manuseio operacional ou a substituição de materiais tóxicos por atóxicos e de materiais não renováveis por renováveis;

- Modificações tecnológicas: utilização de equipamentos mais eficientes do ponto de vista da otimização dos recursos utilizados, uso de controles e de automação que permitam rastrear perdas ou reduzir o risco de acidentes de trabalho.

No caso de modificações do produto, também no nível 1, a autora indica que devem ser consideradas sua substituição - cancelamento do produto ou substituição de um produto tóxico por 
um atóxico -, ou o seu redesenho. Caso a geração de resíduos não possa ser evitada, estes devem ser reintegrados ao processo produtivo da empresa, correspondendo ao nível 2. Apenas como última opção devem ser utilizadas medidas de reciclagem fora da empresa - nível 3.

Lemos (1998) indica alguns benefícios da aplicação das técnicas de Produção mais Limpa na organização, como a geração de inovações tecnológicas; benefícios comerciais e melhoria da competitividade; redução de custos; novas oportunidades de negócios; desenvolvimento econômico mais sustentado; melhoria da imagem da empresa; melhoria da qualidade ambiental do produto; aumento da eficiência ecológica; dentre outros.

Esses benefícios, entretanto, não são imediatos, pois durante a realização dos investimentos ocorrem gastos com alterações de máquinas, substituição de matérias-primas, alteração de processos, dentre outros. Quando se inicia a implantação de ações de Produção mais Limpa a princípio ocorre uma redução dos custos totais, através da adoção de medidas que não necessitam investimento, como ações de boas práticas operacionais, que podem ser atingidas com o treinamento e conscientização dos funcionários. Em seguida, porém, incide um incremento nos custos totais, devido às adaptações necessárias, incluindo a adoção de novas tecnologias e as modificações nos produtos e processos existentes. Gradativamente ocorre então a redução destes custos totais, resultado da otimização dos processos e da adoção de novas tecnologias, o que permite a recuperação do investimento inicial e inclusive, ganhos pela redução permanente dos custos totais.

Demonstra-se que a implementação de ações de caráter ambiental não implica necessariamente em maiores custos, especialmente no médio e longo prazos. Ao contrário, a implantação de um projeto planejado e estruturado deve reduzir custos e melhorar a imagem da empresa perante um mercado que tende a se tornar cada vez mais exigente quanto à gestão ambiental das empresas.

\section{Procedimentos metodológicos}

Este trabalho consiste em estudo descritivo, envolvendo elementos de uma pesquisa bibliográfica, documental e de um estudo de caso descritivo. Com relação ao método de pesquisa, pode-se afirmar que este tem caráter qualitativo.

Para a realização do estudo, selecionou-se o tema Produção mais Limpa como foco principal, com a aplicação do estudo de caso no Laboratório de Camarões Marinhos da Universidade Federal de Santa Catarina, em Florianópolis, durante o primeiro semestre de 2009. Pesquisou-se as iniciativas ambientais implementadas no laboratório durante o período de certificação do Sistema de Gestão Ambiental através da ISO 14001, ou seja, de setembro de 2003 a setembro de 2006. 
Os elementos a serem entrevistados foram definidos de forma propositada e intencional, tendo sido selecionados para responderem às entrevistas o atual gerente administrativo do laboratório e o responsável pela implantação e gestão do SGA. Para a sua consecução utilizou-se, primeiramente, a coleta de dados secundários - documentos fornecidos pelos entrevistados. Já a coleta de dados primários foi realizada através de observação individual não-participante e de entrevistas inicialmente não-estruturadas e, posteriormente, entrevistas semi-estruturadas. Com relação à análise dos dados, esta consistiu em uma análise do discurso, pois se buscou explorar o sentido dos fenômenos encontrados através da coleta de dados primários e secundários.

\section{Estudo de caso}

O Laboratório de Camarões Marinhos - LCM - foi inaugurado em 1985 em FlorianópolisSC, visando promover o desenvolvimento do cultivo de camarões marinhos na região sul do Brasil. Dedica-se ao desenvolvimento de tecnologia para reprodução e cultivo da espécie Litopenaeus vannamei, e a responsabilidade e a tecnologia dessa produção são direcionadas para a pesquisa, treinamento, planejamento e extensão (LCM, 2009).

Em junho de 2002, a partir da iniciativa de um biólogo, em parceria com o Laboratório de Gestão da Qualidade Ambiental da Universidade Federal de Santa Catarina (LGQA), foi elaborada uma proposta de implantação e certificação de um Sistema de Gestão Ambiental no LCM. Esta foi aceita pelos gestores do laboratório e, em setembro de 2003, foi adquirido o certificado ISO 14000. Em 2005 um vírus conhecido popularmente como Síndrome da Mancha Branca atingiu o litoral catarinense, fazendo o laboratório interromper sua produção. Por consequência, em 2006 o então gerente ambiental, responsável pela proposta de implantação do sistema e por todas as atividades que se seguiram após seu aceite, deixou a organização, finalizando um ciclo de melhorias ambientais no laboratório, reforçado pelo vencimento da certificação da ISO 14000 naquele mesmo ano.

\subsection{Implantação do Sistema de Gestão Ambiental}

Quando da implantação do Sistema de Gestão Ambiental do Laboratório de Camarões Marinhos, em 2003, foi definida uma política ambiental para guiar suas atividades, a qual compreende, resumidamente:

a) A busca pela melhoria contínua;

b) O desenvolvimento científico e tecnológico que auxilie o uso racional dos recursos naturais e matérias-primas utilizadas, em busca da prevenção da poluição;

c) $\mathrm{O}$ atendimento às legislações ambientais aplicáveis ao setor e às suas atividades em específico, assumindo uma postura pró-ativa de prevenção às exigências futuras; 
d) Proporcionar sinergia e respeito entre os participantes dentro de um ambiente saudável e seguro, que garanta a convergência dos esforços para a minimização de danos ao meio ambiente.

Entende-se que esta política foi atendida em todos os seus aspectos, como explanado resumidamente a seguir.

Foram realizados programas de sensibilização e treinamentos ambientais, a fim de envolver os funcionários na consecução do SGA. Além disso, foram realizadas também ações junto à comunidade, como visitação ao LCM e palestras para crianças de diversas escolas e alunos universitários.

Os processos do laboratório foram adequados às legislações municipal, estadual e federal e, inclusive, às normas internacionais voltadas ao cultivo de camarão e larvicultura, visto que os auditores da ISO dão elevada importância para o atendimento às questões legais. Além disso, foram tomadas diversas precauções para eliminar as chances de ocorrência do escape de organismos exóticos para o meio ambiente, visto que a espécie de camarões criada pelo LCM não é proveniente do Brasil, e não pode ser transferida para o meio natural no nosso país. Esse escape para a Lagoa da Conceição seria considerado uma falha grave, e ocasionaria o fechamento do laboratório.

A redução dos danos causados ao meio ambiente ocorreu como conseqüência das diversas iniciativas de prevenção e controle da poluição implantadas durante os três anos de certificação, das quais destacam-se: a redução no consumo de energia elétrica e de água doce; o reaproveitamento de água e materiais; o uso de energias mais limpas; a diminuição no uso e/ou substituição de produtos - químicos ou não - empregados no processo por produtos menos impactantes; a eliminação do escape de organismos exóticos para o meio ambiente; a ampliação e aprimoramento do sistema de tratamento dos efluentes sanitários e do processo produtivo; e a implantação de um Programa de Gerenciamento de Resíduos, promovendo a separação, coleta e destinação dos resíduos gerados no LCM.

Verificou-se, com base nos dados históricos fornecidos pelos entrevistados, que a maioria dos objetivos e metas de melhoria ambiental foi alcançada, correspondendo a $86 \%$ de todos aqueles propostos através do seu SGA. Nesse período foram realizadas 31 auditorias internas, a fim de manter o funcionamento correto do sistema. Além disso, foi feito o treinamento operacional e ambiental de todos os colaboradores, além da realização de 24 projetos de sensibilização do público externo sobre as questões ambientais.

A quantidade média de água doce consumida por milhão de pós-larvas produzidas totalizou $20 \mathrm{~m}^{3}$. Não foi possível adquirir dados referentes a quantidade consumida anteriormente à implantação do Sistema de Gestão Ambiental, visto que o controle do consumo de energia elétrica e água do LCM era realizado, naquele período, pela própria Universidade, e essas informações não foram disponibilizadas. $\mathrm{O}$ entrevistado exemplifica, entretanto, que apenas com a criação de um 
sistema de recirculação da água usada no resfriamento do destilador reduziu-se o desperdício de água em aproximadamente seis mil litros por mês. Destaca-se que estes dados são anteriores à Síndrome da Mancha Branca, correspondendo ao período de elevado volume de produção do laboratório.

Apenas 5\% dos resíduos recicláveis do LCM não foram destinados para a reciclagem, tendo sido direcionados ao lixo comum, muitas vezes por estarem sujos ou impróprios para a reciclagem. Todos os resíduos perigosos e orgânicos, entretanto, tiveram destinação correta.

\subsection{Produção mais Limpa versus Controle da Poluição}

Verificou-se que Produção mais Limpa se refere à prevenção de poluição em toda a cadeia produtiva de determinado produto, neste caso, o camarão. Sendo assim, pesquisou-se os seguintes aspectos dos produtos do Laboratório de Camarões Marinhos: o fornecimento de matérias-primas, os insumos utilizados, o consumo de água e energia, o processo produtivo, a escolha e manutenção de máquinas e equipamentos, os resíduos e efluentes gerados no processo, a distribuição dos camarões e a existência ou não de programas de conscientização do consumidor. Através da figura 2 visualiza-se mais claramente os aspectos analisados.

Figura 2 - Aspectos de Produção mais Limpa analisados no LCM
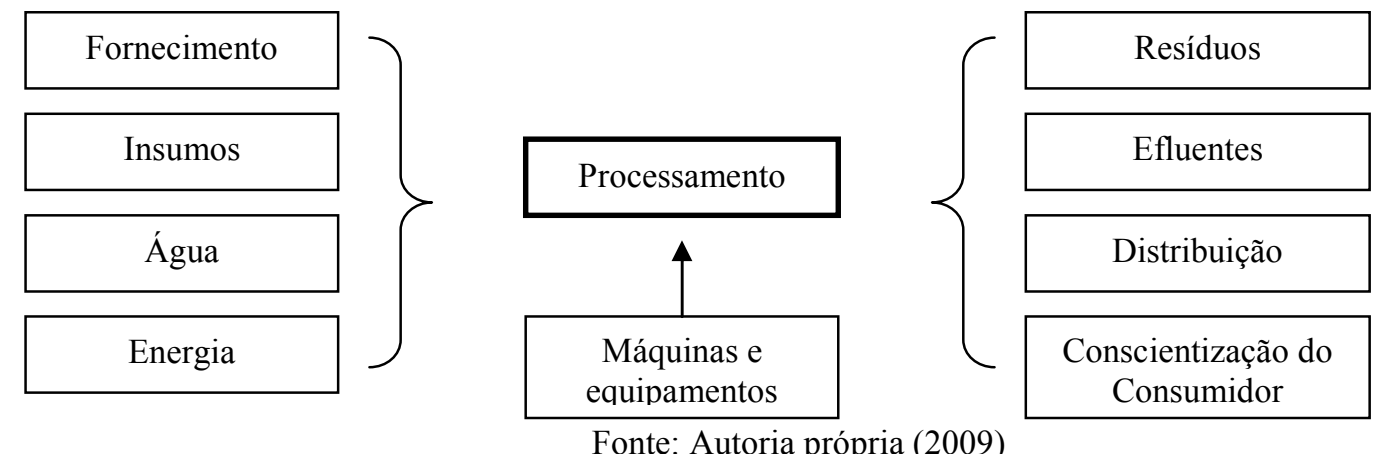

A primeira etapa do ciclo de vida do produto através da perspectiva da Produção mais Limpa se refere à preocupação da empresa com a responsabilidade ambiental de seus fornecedores. No caso do Laboratório de Camarões Marinhos, a única exigência era de que todos os fornecedores possuíssem Licença Ambiental de Operação e, para aqueles que realizavam transporte de material perigoso ou produtos químicos era exigida, também, a Licença Ambiental de Transporte. Além disso, era feita a verificação, por amostragem, da poluição emitida pelos caminhões dos fornecedores. Nos casos em que se emitia mais fumaça do que o necessário, o gerente ambiental do LCM emitia uma notificação para a empresa fornecedora solicitando a regulagem do caminhão sob a pena de troca de fornecedor, caso esta não fosse realizada. O entrevistado supracitado destaca a importância desse processo, considerando que é responsabilidade do laboratório a poluição gerada por seus fornecedores para entregar os produtos adquiridos. Era utilizada uma Tabela de Controle 
dos Fornecedores (TCF) que indicava o produto ou serviço oferecido por determinado fornecedor, sua razão social, o contato na empresa, os pré-requisitos determinados pelo LCM - em sua maioria Licenças Ambientais de Operação e de Transporte - a data de vencimento da licença e observações adicionais sobre sua operação, normalmente indicando a forma de agir caso os caminhões dos fornecedores estivessem emitindo muita fumaça.

Já o impacto ambiental dos insumos utilizados no processo produtivo foi conhecido através do levantamento de aspectos e impactos ambientais das atividades. A partir da participação de técnicos de diversas áreas - químico, bioquímico, biólogo, engenheiro - era determinado o grau de significância de cada aspecto da atividade, permitindo analisar e quantificar o impacto de cada insumo sobre o meio ambiente. Era realizada, também, a análise do que estava sendo consumido e de que maneira este consumo poderia ser reduzido.

Nesse sentido foi reduzido o consumo de energia através da implantação de novas placas para o aquecimento dos tanques onde são mantidos os camarões. Posteriormente substituiu-se o sistema de energia elétrica para aquecimento da água por um sistema que utilizava apenas gás natural. Com o intuito de proporcionar maior redução sobre o consumo e o impacto do aquecimento da água sobre o meio ambiente substituiu-se novamente esse sistema por equipamentos denominados "trocadores de calor", que captam o calor do meio para transformá-lo em energia elétrica. Com relação a iluminação dos setores produtivos foi aproveitada a luz natural através da instalação de placas transparentes em partes do telhado do laboratório. Além disso, foi levada ao LCM a campanha da Universidade Federal de Santa Catarina para economia de energia na área administrativa do laboratório, a partir da aplicação de adesivos da campanha próximos aos interruptores.

O uso de alguns produtos químicos também foi reduzido e, em alguns casos, substituído por outros menos impactantes. O cloro utilizado para limpeza e desinfecção das botas dos funcionários na entrada do laboratório, por exemplo, foi substituído pela substância denominada amônia quaternária (TRIQUART B), que possui maior vida útil quando misturada à água, reduzindo a quantidade necessária de produto. Para a limpeza dos tanques também foi feita a substituição do cloro, ácido e álcool pela substância TOPAX 68 (composta por cloro e detergente) e pelo NEXOBIL (detergente especial), ambos com menor impacto ambiental e à saúde do funcionário.

Além disso, substituiu-se o uso de produtos químicos para limpeza das tubulações de captação de água pelo uso de buchas, que realizavam a limpeza física por fricção. E, para as tubulações de ar, foi substituída a desinfecção química pelo uso de buchas contendo álcool.

Com o intuito de reduzir o consumo de água através do tratamento e reutilização da água de esgoto proveniente dos banheiros do LCM, foram instaladas unidades modulares de tratamento de efluentes, que reduziam a contaminação do lençol freático com coliformes fecais. Realizado o 
tratamento da água nas unidades modulares, esta ainda era ozonizada para eliminar o restante das bactérias. Destaca-se que o ozônio tem elevada eficiência como desinfetante, além de não emitir poluição, já que se transforma em oxigênio. Esta água não podia ser utilizada no processo produtivo, devido às elevadas exigências de higiene e qualidade da água no processo, mas podia ser utilizada para molhar a grama, por exemplo.

Outra iniciativa implantada a fim de reduzir o consumo de água foi o redirecionamento do excedente de água salgada bombeada pelo LCM para o Laboratório de Peixes Marinhos LAPMAR, evitando desperdício desse recurso natural. E foi desenvolvido, também, um sistema de recirculação da água utilizada para resfriamento do destilador, reduzindo a quantidade de água necessária para esse procedimento, com economia de aproximadamente seis mil litros de água por mês.

O gerente ambiental afirma que havia preocupação com a eficiência ambiental de máquinas e equipamentos já existentes no processo ou que fossem ser adquiridos. Um exemplo foi a aquisição de tanques de fibra para o setor de microalgas. Antes dessa iniciativa ser tomada eram utilizados sacos plásticos grossos o suficiente para comportar em torno de 150 litros de água, sendo que estes eram trocados diariamente e enviados para reciclagem. A fim de reduzir o consumo de plástico e a geração de resíduos substituiu-se os sacos pelos tanques de fibra transparentes, ainda que esse processo reduzisse parcialmente a produtividade do setor, visto que as microalgas necessitam de luz para se reproduzirem, e os sacos plásticos eram mais eficientes nesse quesito. A redução de produtividade, porém, foi insignificante perante a diminuição do consumo de plástico, pois deixou-se de consumir 25 sacos plásticos por dia.

Em alguns casos, porém, o valor do investimento em uma tecnologia ou equipamento limpo era muito alto, tornando-se proibitivo para o laboratório. E, em outros casos, ainda não estão disponíveis no mercado as tecnologias limpas necessárias para que seja eliminado ou reduzido o impacto ambiental de determinada atividade.

Com relação à água utilizada no processo produtivo, repleta de nutrientes, deixou de ser descartada e passou a ser tratada internamente através de um tratamento natural utilizando as chamadas "lagoas de estabilização". Todos os efluentes eram direcionados para estes locais, onde os peixes consumiam as pequenas larvas que poderiam sair do processo de produção dos camarões. A utilização de aeradores fazia a função de movimentar a água a fim de manter sua oxigenação e evitar a geração de gases tóxicos e mortandade de peixes. Também eram utilizadas macroalgas que cresciam em abundância no terreno do LCM, com o intuito de se realizar a remoção de forma natural da carga de nutrientes resultantes do processo. Já a água proveniente da produção de reprodutores passou a ser tratada de forma biológica por um sistema de infiltração e absorção por raízes, em que foram levadas plantas que normalmente crescem na beira da Lagoa da Conceição 
para o terreno do LCM, devido ao fato de consistirem em plantas que crescem com muita rapidez e consomem uma quantidade elevada de nutrientes.

A fim de minimizar o impacto dos resíduos que não puderam ser evitados durante o processo, foi implementado o Programa de Gerenciamento de Resíduos, visando promover a separação, coleta e destinação dos materiais recicláveis, rejeitos perigosos e demais resíduos gerados no laboratório. O lixo foi, então, classificado em reciclável, rejeito ou orgânico.

O reciclável era composto por papéis, plásticos, alumínio e vidro limpos. Os rejeitos abrangiam materiais molhados ou outros que não poderiam mais ser reciclados, sendo encaminhado para o lixo comum. O resíduo orgânico, formado por restos de alimentos inclusive do processo produtivo - processo de berçário (larvas) e alimentação do processo de maturação (contendo restos de lula, peixes) - era recolhido e enviado para covas criadas dentro do terreno do laboratório. Este lixo era enterrado em camadas, e servia como adubo para a restinga local. Era utilizado, para controle das áreas escavadas, um mapa que indicava onde poderia ser realizada a próxima cova, e há quanto tempo havia sido feita a primeira, pois poderiam retornar àquela após determinado período. Era feita, também, a destinação correta de pilhas e baterias e do lixo perigoso de laboratório, como seringas e lâminas. Os rejeitos químicos, por sua vez, incluindo cloro e detergentes, eram colocados em bombonas plásticas e recolhidos por uma empresa de coleta contratada pela UFSC, que os inertizava. As bombonas utilizadas como embalagem também eram inertizadas, sendo retornadas ao LCM aquelas que poderiam ser reutilizadas, com base nos produtos químicos que continham.

A fim de minimizar a poluição sonora emitida durante o processo produtivo, foram instalados abafadores de ruído no sistema de geração de energia elétrica.

Para o processo de distribuição dos produtos, destacava-se a aquisição da Licença Ambiental de Transporte e a manutenção preventiva constante dos caminhões, para que estivessem regulados a fim de emitir o mínimo de poluentes possível.

O processo de conscientização e sensibilização de consumidores ocorria de maneira informal, feita apenas durante as reuniões da Associação de Produtores de Camarão, realizadas na cidade de Laguna-SC. Nestas, apresentava-se o sistema de gestão ambiental implantado no LCM, demonstrando seus benefícios como forma de incentivo para que as demais organizações tomassem iniciativas semelhantes.

A partir da identificação das alterações realizadas no processo produtivo do LCM com a implantação do sistema de gestão ambiental, pode-se classificar essas ações com base na diferença entre a perspectiva do controle da poluição (técnica "fim-de-tubo") e a produção mais limpa. Apresenta-se a seguir um quadro contendo essa classificação.

Quadro 1 - Controle da poluição versus Produção mais Limpa 


\begin{tabular}{|c|c|}
\hline Controle da Poluição & Produção mais Limpa \\
\hline $\begin{array}{l}\text { Tratamento natural da água proveniente do processo } \\
\text { produtivo, através de lagoas de estabilização e } \\
\text { tratamento por raízes. }\end{array}$ & $\begin{array}{l}\text { Manutenção preventiva das máquinas e equipamentos, } \\
\text { e preocupação com sua eficiência ambiental. }\end{array}$ \\
\hline Programa de Gerenciamento de Resíduos. & $\begin{array}{l}\text { Redução do consumo de energia e substituição por } \\
\text { fontes menos poluidoras. }\end{array}$ \\
\hline \multirow[t]{4}{*}{$\begin{array}{l}\text { Instalação de abafadores de ruído no sistema de } \\
\text { geração de energia elétrica. }\end{array}$} & $\begin{array}{l}\text { Redução do consumo de água através do } \\
\text { redirecionamento do excedente para o LAPMAR e do } \\
\text { sistema de recirculação da água usada no esfriamento } \\
\text { do destilador. }\end{array}$ \\
\hline & $\begin{array}{l}\text { Redução de uso e substituição de produtos químicos } \\
\text { por outros menos poluentes. }\end{array}$ \\
\hline & $\begin{array}{l}\text { Substituição de matérias-primas descartáveis por } \\
\text { outras com maior durabilidade. }\end{array}$ \\
\hline & $\begin{array}{l}\text { Tratamento e reutilização da água do esgoto dos } \\
\text { banheiros do LCM. }\end{array}$ \\
\hline
\end{tabular}

Fonte: Autoria própria (2009)

Nesse sentido compreende-se que a gestão ambiental do LCM age de acordo com a estratégia da produção mais limpa abordada na figura 1. Esse sistema inicia suas atividades na tentativa de minimização dos resíduos e emissões. O primeiro nível, portanto, comporta a redução na fonte, a partir de modificações no processo ou produto. Verifica-se no laboratório que as suas ações de diminuição do consumo de energia, água e produtos químicos, bem como a substituição de insumos e tecnologias por outros menos impactantes adaptam-se a esta primeira preocupação da produção mais limpa.

O segundo nível - que engloba a reciclagem interna para os resíduos e emissões gerados - é demonstrado, no LCM, a partir do tratamento interno da água do esgoto dos banheiros do laboratório, através de instalações modulares. Já o terceiro nível se refere à reciclagem externa, como no caso do Programa de Gerenciamento de Resíduos do LCM. Neste caso, além da destinação correta dos resíduos que não puderam ser evitados durante o processo, ocorre a reutilização de alguns insumos, como por exemplo as bombonas plásticas utilizadas para transporte de rejeitos químicos por uma empresa especializada.

Percebe-se, então, que o Sistema de Gestão Ambiental do Laboratório de Camarões Marinhos não foi focado no controle da poluição, a fim de cumprir as determinações legais, mas se baseou, sim, na prevenção da poluição, ou Produção mais Limpa, procurando reduzir ao máximo o impacto de suas atividades sobre o meio ambiente.

\section{Considerações finais}

Com base nesta análise concluiu-se que foi realizado um trabalho bastante completo de implantação do SGA no laboratório, em 2003, visto que contemplou todo o ciclo de vida do camarão produzido: houve preocupação com o impacto ambiental dos fornecedores e a qualidade ambiental das matérias-primas utilizadas, redução de impacto através de substituição de 
equipamentos e matérias-primas por outras menos poluentes, reaproveitamento de insumos, destinação correta dos resíduos, tratamento de efluentes e preocupação com a distribuição dos produtos e a sensibilização dos consumidores.

Foram desenvolvidas práticas relacionadas à responsabilidade ambiental de fornecedores; melhorias no processo produtivo, a fim de torná-lo mais limpo - reduzindo o consumo de insumos e a geração de resíduos -; práticas de destinação correta dos resíduos e de controle da poluição durante a distribuição dos produtos. Com isso foi possível verificar que a preocupação ambiental do laboratório foi de Produção mais Limpa, pois priorizou a redução da poluição em detrimento do simples tratamento da poluição já emitida.

A política ambiental do laboratório, definida quando da implantação do sistema, foi plenamente atendida até 2005, contemplando a sensibilização de stakeholders, atendimento à legislação, prevenção de poluição e minimização de danos ambientais.

Naquele ano, entretanto, a Síndrome da Mancha Branca atingiu o litoral catarinense, e o laboratório teve de interromper sua produção. Por consequência, o então gerente ambiental, responsável pela proposta de implantação do sistema e por todas as atividades que se seguiram após seu aceite, também teve de deixar a organização.

Destaca-se que a eficácia do Sistema de Gestão Ambiental durante o período de certificação - 2003 a 2006 - não foi mérito dos gestores do laboratório, visto que não houve interesse e participação efetivos dos mesmos nas práticas ambientais. Estes viabilizaram a implantação das práticas ambientais, porém a responsabilidade pelas iniciativas e monitoramento do alcance dos objetivos ambientais do LCM era o gerente ambiental, contratado especialmente para realizar essa tarefa.

Com a saída do gerente ambiental SGA do laboratório se estagnou. A produção foi retomada em novembro de 2008, porém o mesmo não ocorreu com o Sistema de Gestão Ambiental. Atualmente vêm sendo mantidas as iniciativas de Produção mais Limpa implantadas durante o período de certificação, porém não existem quaisquer objetivos de melhorias futuras, ou mesmo algum responsável pelo sistema. Verificou-se, assim, o surgimento de uma postura ambiental reativa no laboratório.

Acredita-se que, após a implantação de um projeto de gestão ambiental estruturado, como foi feito no LCM, não deveria ter sido permitida a estagnação do sistema. Os investimentos mais altos - de certificação, mapeamento e padronização de processos e substituição de insumos e equipamentos, como identificados na fundamentação teórica -, já haviam sido feitos, bastando o interesse e a competência gerencial para que o sistema fosse mantido em funcionamento.

Sugere-se, portanto, a reimplantação do Sistema de Gestão Ambiental do LCM, ainda que sem a certificação pela ISO 14000, mas focando nas necessidades e baseando-se na disponibilidade 
financeira e de recursos humanos do laboratório. Percebe-se a necessidade de que a Universidade Federal de Santa Catarina apóie essa reimplantação, visto que é de sua responsabilidade a manutenção da qualidade dos órgãos por esta mantidos.

\begin{abstract}
Along and because of the Industrial Revolution, on the $18^{\text {th }}$ century, there was an increase of the number of products offered and also of the natural resources usage, generating environmental impacts that, after the 60's and 70's, became relevant to manhood's attention, increasing environmental concerning among people and governments. After the 90's, business, governmental and non-governmental initiatives stood out on the search of a better relationship between men and the environment, calling attention to terms as Environmental Management and Cleaner Production. Aiming to brighten the view on how cleaner production happens inside organizations, this research has been based on the Marine Shrimp Laboratory of the Universidade Federal de Santa Catarina. This study, therefore, is a case, a bibliographic, exploratory and descriptive study, that includes quality features. The data collection was based on documents researching, individual and non participant observation and semi-structured interviews, questioning intentionally chosen interviewees, which established a speech's analysis. The environmental activities of the laboratory have been studied and analyzed under the cleaner production concept, and the results achieved showed the influence of the environment on its Environmental Management System.
\end{abstract}

Key-words: cleaner production; environmental management system; pollution control.

\title{
Referências
}

BARBIERI, J. C. Desenvolvimento e meio ambiente: as estratégias de mudanças da Agenda 21. 9. ed. São Paulo: Vozes, 2008.

CNTL - CENTRO NACIONAL DE TECNOLOGIAS LIMPAS. O que é Produção mais Limpa?. Disponível em: $<$ http://srvprod.sistemafiergs.org.br/portal/page/portal/sfiergs_senai_uos/senairs_uo697/O\%20que $\% 20 \%$ E9\%20Produ\%E7\%E3o\%20mais\%20Limpa.pdf $>$. Acesso em: 23 mar. 2009.

CORAZZA, R. I. Gestão ambiental e mudanças da estrutura organizacional. RAE Eletrônica, v. 2, n.2, jul-dez. 2003. Lresset

FIGUEIREDO, V. F. Produção mais limpa nas pequenas e micro empresas: elementos inibidores. In: ENCONTRO NACIONAL DE ENGENHARIA DE PRODUÇÃO, 24, 2004, Florianópolis. Anais... Florianópolis: ENEGEP, 2004.

GUIA DA PRODUÇÃO MAIS LIMPA. Entenda o conceito de PmaisL. Disponível em: $<$ http://www.pmaisl.com.br/guia-eletronico-pmaisl/abert.html>. Acesso em: 22 mar. 2009.

IBPS - INSTITUTO BRASILEIRO DE PRODUÇÃO SUSTENTÁVEL E DIREITO AMBIENTAL. Produção consciente é ecoeficiente. Disponível em: <http://www.ibps.com.br/index.asp?idmenu=sga/sga>. Acesso em: 27 nov. 2008.

LCM - LABORATÓRIO DE CAMARÕES MARINHOS. Histórico. Disponível em: $<$ http://www.lcm.ufsc.br/index.php?area=9\&id=12>. Acesso em: 31 mar. 2009.

LEMOS, A. D. Cunha. A produção mais limpa como geradora de inovação e competitividade: o caso da fazenda Cerro do Tigre. 1998. 182 f. Dissertação (Mestrado em Administração) - Programa de Pós-Graduação em Administração, Universidade Federal do Rio Grande do Sul, Porto Alegre.

LUSTOSA, M. C. J. Industrialização, meio ambiente, inovação e competitividade. In: MAY, Peter H.; LUSTOSA, Maria Cecília; VINHA, Valéria da. (Orgs.) Economia do Meio Ambiente: teoria e prática. Rio de Janeiro: Campus, 2003. p. $155-172$.

MAIMON, D. ISO 14001 passo a passo da implantação nas pequenas e médias empresas. Rio de Janeiro: Qualitymark Editora Ltda., 1999.

Passaporte verde: gestão ambiental e competitividade. Rio de Janeiro: Qualitymark, 1996. 
RENSI, F. Gestão da produção mais limpa: uma proposta para o processo fabril. 2006. 155 f. Dissertação (Mestrado em Administração) - Curso de Pós-Graduação em Administração, Universidade Federal de Santa Catarina, Florianópolis.

SILVA, A. Gestão da produção mais Limpa: o caso WEG. 2004. 184f. Dissertação (Mestrado em Administração) Curso de Pós-Graduação em Administração, Universidade Federal de Santa Catarina, Florianópolis.

\section{Dados dos autores:}

Nome completo: Luciane Finger

Filiação institucional: Sistema Federação das Indústrias do Estado do Paraná - FIEP

Departamento: Gerência de Responsabilidade Social Empresarial do SESI-PR

Função ou cargo ocupado: Trainee

Endereço completo para correspondência: Rua Comendador Fontana, 50, ap. 52. Centro Cívico.

Curitiba-PR. 80030-070.

Telefones para contato: (41) 9955-3283

e-mail: luciane_finger@yahoo.com.br

Nome completo: Luis Moretto Neto

Filiação institucional: Universidade Federal de Santa Catarina - UFSC

Departamento: Departamento de Ciências da Administração

Função ou cargo ocupado: Professor Associado II

Endereço completo para correspondência: Departamento de Ciências da Administração/CSE. Universidade Federal de Santa Catarina. Trindade. Florianópolis-SC. 88040-970

Telefones para contato: (48) 3721-9374

e-mail: moretto@cse.ufsc.br

Recebido para publicação em: 01/08/2010

Aceito para publicação em: 27/11/2010 